\title{
Turismo y Desarrollo Local: un Estudio de Caso en el Distrito de Pisac - Cusco
}

\section{Tourism and Local Development: a Case Study in the District of Pisac - Cusco}

\author{
Vilma Luz Aparicio Salas ${ }^{1}$ 0000-0002-8993-0874 \\ ${ }^{1}$ Universidad Nacional San Antonio Abad del Cusco, Perú.
}

luzlose9009@gmail.com

Recibido el: 10/09/2021

Aceptado el: 15/11/2021

Publicado el: 15/12/2021

\section{Resumen}

El desarrollo local está ligado a la articulación de los factores sociales, económicos y políticos, allí juega un rol importante el aspecto económico y sus recursos locales. El objetivo del articulo consiste en establecer la relación que existe entre la promoción turística y el desarrollo local, debido a la interacción de los agentes de promoción turística. La metodología de investigación es el cuantitativo de tipo correlacional y transeccional, las técnicas de recolección de datos fue la encuesta y la escala de Likert, los datos se recolectaron de los artesanos de la localidad que previamente fueron muestreados. El resultado obtenido muestra que existe una correlacional positiva y significativa en la promoción turística y el desarrollo local, es decir, que las actividades realizadas por parte de la municipalidad contribuyeron en el desarrollo de la localidad. Se concluye que cuanto mayor y mejor se hace la promoción turística, mayor o mejor será el desarrollo local.

Palabras clave: desarrollo local; participación ciudadana; promoción turística.

\begin{abstract}
Local development is linked to the articulation of social, economic and political factors, where the economic aspect and its local resources play an important role. The objective of the article is to establish the relationship that exists between tourism promotion and local development, due to the interaction of tourism promotion agents. The research methodology is the quantitative correlational and transectional type, the data collection techniques were the survey and the Likert scale, the data was collected from the local artisans who were previously sampled. The result obtained shows that there is a positive and significant correlation in tourism promotion and local development, that is, that the activities carried out by the municipality contributed to the development of the town. It is concluded that the greater and better the tourism promotion is done, the greater or better the local development will be.
\end{abstract}

Keywords: local development; citizen participation; tourism promotion. 


\section{Introducción}

El desarrollo local está ligado a la articulación de los factores sociales, económicos y políticos. En este contexto, el aspecto económico y sus recursos juega un rol importante en la calidad de vida de la sociedad, donde se desarrollan diversas actividades, como la industria, la agricultura, turismo y entre otras. El desarrollo local es el conjunto de mejoramiento del nivel y calidad de vida de los habitantes de una localidad, a raíz de crecimientos sustentables que implican el cambio de las condiciones sistémicas y estructurales de la localidad (Solari \& Pérez, 2005). Hace referencia a cómo la sociedad y las instituciones públicas trabajan de la mano para poder desarrollarse, mediante la intervención profesional y planes estratégicos para el bien común (Carvajal, 2011).

Sin embargo, aunque se tenga grandes potencialidades en recursos, como en este caso el turismo, si no es aprovechada de manera adecuada, entonces se tendrá un desarrollo local débil o inadecuado. Existen diversas modalidades de turismo, el de aventura, el ecoturismo y el agroturismo, que hacen de esta forma de turismo una opción atractiva para el impulso de la actividad que buscan alcanzar un desarrollo armónico y sostenido. De esta forma, contribuyen al desarrollo local, a partir de su integración armónica con el entorno natural, cultural y humano, cuidando su frágil equilibrio, evitando perjudicar el patrimonio cultural, las costumbres, tradiciones y valores de la comunidad en la que se inserta (Narváez, 2015).

La promoción turística vista como la oferta turística, demanda turística y la valoración patrimonial, que genera un desarrollo local y empleo a la población, es un factor clave para el desarrollo económico y social que beneficia a la población en general (Socatelli, 2013). La oferta turística es el conjunto de productos y servicios asociados a un determinado espacio geográfico y socio-cultural, que permite, facilita y propicia el aprovechamiento de los atractivos turísticos del lugar. La demanda, es la toma de decisiones que los individuos programan acciones de viajes turísticos para disfrutar de recursos turísticos ofertados. La valoración patrimonial, es el valor de los bienes culturales, una cualidad añadida por las personas que puede crecer o disminuir y que los hace estimables (De Lugo, 2000). La promoción turística es una actividad integrada por un conjunto de acciones e instrumentos, cumpliendo la función de favorecer los estímulos para el surgimiento y desarrollo del desplazamiento turístico, así como el crecimiento y mejoría de operación de la industria que lo aprovecha con fines de explotación económica (Gurria, 1997).

Existen estudios sobre la promoción turística y el desarrollo local en otras realidades, como es el caso de Turismo sostenible y desarrollo local en el distrito de Ccorca - Cusco, donde se demuestra la relación directa positiva entre productos turísticos con potencial de desarrollo y el desarrollo económico; asimismo, relación entre la promoción turística municipal y el desarrollo social, es directa positiva y si se produce un turismo sostenible se generará un desarrollo local (Calderón, 2017). Otro estudio en Argentina sobre turismo y desarrollo local en Chacabuco, en un análisis integral para el territorio demuestra que Chacabuco y su área circundante muestra una serie de rasgos ambientales, sociales y culturales que le otorgan potencialidad turística. De la evaluación de los recursos turísticos locales surge que Chacabuco muestra una interesante oferta de recursos, primordialmente de índole cultural (Forneris, 2012). Asimismo, Sanchis y Olcina (1995) determinaron que el turismo rural es el apoyo a zonas de escaso nivel de desarrollo, donde el nivel de población es bajo, debido a la constante emigración de los habitantes a grandes urbes, para evitar ello es necesario salvaguardar el patrimonio cultural, fomentar la artesanía local y ofrecer estos servicios al visitante.

En ese contexto, el distrito de Pisac de la región de Cusco - Perú posee diversos atractivos turísticos patrimoniales, tales como parque arqueológico de Pisac compuesto por sitios arqueológicos como Intihuatana, Inka Qonqorina, K'allak'asa, Kantusraqay, Hospitalniyoq, Qoriwayrachina, Q'entemuyurina, red de caminos y andenes agrícolas, así como, una variedad de productos artesanales: textiles, platería, cerámica etc. y los servicios turísticos como alojamientos, restaurantes, locales de esoterismo, bares, etc., que son excelentes productos turísticos culturales para los visitantes nacionales y extranjeros que aprecian dichos recursos.

Asimismo, existen referencias históricas culturales de diferentes aportes teóricos realizados desde la arqueología, la etnohistoria, sobre el origen de los pobladores del lugar hasta el periodo inca, la tradición oral sobre el relato de la ñusta encantada, reseña del Cacique Bernardo Tambohuacso 
Pumayali y se observa que los turistas locales y regionales consumen dichos bienes y servicios turísticos ofrecidos. De esta forma, el desarrollo local alcanzado en este distrito depende por un lado de una adecuada promoción turística $\mathrm{y}$, por otro lado, de la planificación implementada por el gobierno local y sus pobladores para aprovechar de los recursos culturales.

El objetivo del artículo es establecer la relación entre la promoción turística y el desarrollo local en el distrito de Pisac - Cusco Perú, 2019, debido a la interacción de los agentes de promoción turística que dinamizan la economía local. El articulo contribuye para la información del segmento turismo, que en el circuito turístico de Cusco - Machupichu existe productos y servicios turísticos apropiados para los visitantes, hecho que no se conocía en la literatura del área cuando se abordaba el turismo en la región del Cusco - Perú.

Luego de la introducción el artículo se estructura de la siguiente forma en la primera parte trata del marco teórico, luego se presenta la metodología de la investigación, posteriormente los resultados y discusión y finalmente, la conclusión, componentes que caracteriza el presente trabajo.

\section{Marco teórico}

\section{Promoción turística}

La promoción turística forma parte fundamental del crecimiento del turismo en el mundo. Es la manera adecuada de comunicar a los potenciales turistas que la oferta propuesta es capaz de satisfacer sus exigencias y sus demandas, es tratar de convencer al turista de que merece la pena ir a un destino a visitarlo (Castillo \& Castaño, 2015).

Los autores refieren que, la promoción de un determinado destino turístico está determinada por la difusión del mismo, mediante el uso de medios escritos, hablados o visuales, gracias a esta publicidad, un gran número de personas se sienten atraídas por la variedad de servicios ofertados y son adquiridos por los turistas. Asimismo, destacan que en los últimos años la promoción turística ha comenzado una nueva fase basada principalmente en el internet. Como indican Pérez-García y Torres-Valdés (2019) que es preciso el uso adecuado de Facebook y otras redes sociales como herramienta de interacción con la ciudadanía y el potencial turista, de modo que ésta se convierta en embajadora del territorio, aprovechando la capacidad relacional de esta red social.

Además, Castillo y Castaño (2015) indican que se debe difundir determinada información, desarrollar ciertas actitudes y promover acciones que beneficien a la comunidad receptora. Siendo estos de vital importancia para el sostenimiento de la actividad turística y desarrollo de las localidades donde se acontecen dichas experiencias.

Por otro lado, Gurría (1997) define la promoción turística como una actividad integrada por un conjunto de acciones e instrumentos, que cumple la función de favorecer los estímulos para el surgimiento y desarrollo del desplazamiento turístico, así como el crecimiento y mejoría de operación de la industria con fines económicos.

Siguiendo al autor, se puede entender que la promoción turística que viene a ser una actividad que engloba instrumentos y acciones, cuyo objetivo es estimular el desplazamiento de turistas para mejorar el desarrollo del sector turismo, además, de fortalecer la industria. Gurria (1997) resalta tres elementos de promoción turística y son: 1) Publicidad, 2) Materiales de apoyo de ventas y 3) Relaciones públicas. Estos elementos convencen a los visitantes que pueden ir de visita a determinados lugares promocionados.

Respecto a los tipos de promoción, Ibañez y Cabrera (2011) señalan los siguientes: promoción turística pública, la privada y la mixta. La publica, se realiza por medio del financiamiento de empresas relacionadas a los gobiernos. Privada, el costo es asumido por empresas privadas, pero también por personas que laboran independientemente. Mixta, la colaboración conjunta es su característica, ya sea de una entidad pública o privada.

En una promoción turística, se debe tener en cuenta la oferta y demanda turística, a fin de tener sostenibilidad en dicha actividad. Socatelli (2013) define oferta turística como el conjunto de productos y servicios asociados a un determinado espacio geográfico y socio-cultural, que tienen por objetivo permitir, facilitar y propiciar el aprovechamiento de los atractivos turísticos y cuyos oferentes quieren vender. En tanto, Sancho (2008) define la oferta turística como, el conjunto de productos turísticos y servicios puestos a disposición del usuario turístico en un destino determinado, para su disfrute y consumo. Pero, 
el turista real y consumidor potencial es quien localmente establece el tiempo que cada producto puede entrar en el mercado (Ibañez \& Cabrera, 2011).

De acuerdo al autor, la oferta turística es un conjunto de bienes como de servicios turísticos que posee una comunidad que son ofrecidos al público en general para su aprovechamiento y su consumo, son dados a conocer a través de medios informativos y con la ayuda de las municipalidades que se encargan de su mantenimiento y su cuidado para brindar al turista mejores experiencias en su visita.

En cuanto a la demanda turística, Sancho (2008) indica que la demanda está ligada a la planificación de la toma de decisiones y las actividades relacionadas a aspectos económicos, que dependerá de la capacidad de gasto que tenga el turista, además de factores internos y externos. Pulido-Fernández y López-Sánchez (2016) ha demostrado que la cadena de valor del destino turístico posibilita los procesos de planificación turística de forma innovadora, para la generación de herramientas útiles al servicio de los gestores turísticos, de manera que estos puedan tomar decisiones con el mayor grado de conocimiento. Por tanto, la demanda es la suma de los bienes y servicios solicitados efectivamente por los consumidores, concretamente en cada uno de los sitios que se visitan (Ibañez \& Cabrera, 2011).

Además, Sancho (2008) clasifica la demanda turística en tres grandes grupos: la demanda efectiva, individuos que se encuentran en la actividad turística; la demanda no efectiva, es el sector de población que no viaja por algún motivo; la demanda potencial, que se refiere a aquéllos que viajarán en el futuro; y la demanda diferida, aquélla que no ha podido viajar por algún problema en el entorno o en la oferta.

\section{Desarrollo local}

El desarrollo requiere de la concurrencia de varios actores que apuesten por objetivos comunes para alcanzar las metas. Según Cárdenas (2002) el desarrollo local es un proceso que se construye diferenciadamente en cada país, según las distintas articulaciones que se producen entre las dimensiones territoriales, la historia, las estructuras y la acción diferenciada de los actores. Y para Albuquerque (2007), el desarrollo local trata de una eficiente coordinación de los diferentes niveles territoriales de las administraciones públicas y de un contexto integrado de las diferentes políticas de desarrollo, no se limita al desarrollo económico local. Se trata de un enfoque integrado en el cual deben considerarse los aspectos ambientales, culturales, socio-institucionales, laborales y de desarrollo humano.

Paredes (2009) destaca que el desarrollo local, cuenta con tres tipos de dimensiones: Económica, Socio-cultural y Político administrativa. La económica, definida como un proceso basado en el crecimiento, además de cambio estructural que, a través del empleo del potencial desarrollo logrado, lleva a realzar el bienestar de los individuos. La dimensión social y cultural del desarrollo local consiste, en suma, en la movilización del potencial creativo y emprendedor de la población local en términos de confianza en sí misma y despliegue de imaginación, iniciativa, cooperación y receptividad a las ideas y propuestas innovadoras (Monge-Rodriguez, 2016). En cuanto a política administrativa, Di Prieto (2001) citando a García, ubica en tres áreas la gestión municipal: la política institucional, la económica y la social. En la primera, significa pasar de una gestión administrativa al modelo gubernativo-gerencial; en la segunda, se requiere transitar del rol pasivo al desarrollo local; finalmente, en el área social, ir del modelo residual a la gerencia social. Los cuales puede permitir cerrar las brechas entre sostenibilidad organizacional y desarrollo sostenible, debido a promoción de iniciativas multisectoriales y multistakeholder de desarrollo (Dueñas-Ocampo et al., 2021).

\section{Metodología}

Pisac es uno de los ocho distritos que compone la provincia de Calca, departamento de Cusco. Se encuentra en la jurisdicción del gobierno regional del Cusco - Perú.

El enfoque de investigación utilizado fue cuantitativo, caracterizado por la utilización de datos recolectados para probar hipótesis con base en la medición numérica y el análisis estadístico, con el fin de establecer pautas de comportamiento y probar teorías (Hernández et al., 2014) y analítica de acuerdo a Hurtado (1998) por que los estudios analíticos se entienden que pretenden hallar pautas de relación interna en un suceso, con el propósito de llegar a un juicio más hondo que la descripción 
básica; por ello se sirven de las matrices de análisis, donde proporcionan los criterios que admiten identificar esas pautas de asociación. En la investigación se analizaron dos variables de estudio para saber si existe una relación entre ellas.

Según Hernández et al. (2010), los estudios correlacionales tienen como finalidad conocer la relación o grado de asociación que exista entre dos o más conceptos, categorías o variables en una muestra o contexto en particular. En ese sentido, se analizan la relación de las variables promoción turística y el desarrollo local, considerando las dimensiones de análisis como la oferta turística, demanda turística y desarrollo local.

El diseño fue definido como una investigación no experimental y transeccional debido a que el estudio no manipuló las variables. Al respecto Hernández et al. (2014) mencionan que son investigaciones donde no se hace variar intencionalmente las variables independientes. Por tal razón, los datos se recolectaron en un solo momento de la unidad de análisis.

\section{Unidad de análisis}

Para realizar la selección de una muestra, en primera instancia se definió la unidad de análisis, conformada por cada uno de los artesanos que elaboran artesanías de diferentes temáticas (platería, cerámica y ropa tradicional) en el distrito de Pisac. La población de estudio está conformada por 230 artesanos, el tamaño de la muestra estratificada se muestra de 145 como se presenta en la Tabla 1.

Tabla 1. Muestreo estratificado.

\begin{tabular}{lccc}
\hline Estratos & Nh & Nh/N & N \\
\hline Platería & 10 & 0.0434 & 6 \\
Cerámica & 105 & 0.4565 & 66 \\
Ropa tradicional & 115 & 0.5000 & 73 \\
Total & 230 & 0.9999 & 145 \\
\hline
\end{tabular}

Fuente. Unidad de análisis.

\section{Técnicas de recolección de información}

Previo a la recolección de datos, el instrumento se sometió al juicio de dos expertos en el área, turismo y desarrollo lo ha que ha permitido la mejor consistencia del estudio y explicar el fenómeno de promoción turística y desarrollo local. Asimismo, se aplicó el Alfa de Crombach al $10 \%$ de la muestra para la validez interna del instrumento, de donde resultó 0.713 de confiabilidad.

Rojas (2013) la información cualitativa y cuantitativa que se recaben en el trabajo de campo deben estar plenamente justificados por los objetivos y las hipótesis de la investigación, porque se corre el riesgo de recopilar datos no útiles para efectuar un análisis adecuado del problema. En ese sentido, las fuentes a las que se tuvo acceso para conseguir la información y lograr los objetivos e hipótesis planteados en la investigación son fuentes primarias, siendo información oral o escrita que fueron recopiladas directamente a través de las unidades de estudio. La técnica empleada fue la encuesta y como instrumento para la recolección de información, el cuestionario compuesto por preguntas cerradas. Según Sekaran (2003) los cuestionarios son un mecanismo eficiente de recolección de datos cuando el investigador sabe exactamente qué se requiere y cómo medir las variables de interés.

\section{Técnicas de análisis e interpretación de la información}

La interpretación se realizó con el fin de encontrar un alcance más completo y amplio de la información empírica recopilada. Después de haber empleado la técnica de la encuesta para recabar información, se analizó e interpretó por separado la información obtenida. Luego de recolectar los datos en base a veintiocho (28) ítems, se prosiguió a la interpretación y análisis por variables y dimensiones.

En cuanto a los procedimientos matemáticos, se empleó una distribución de frecuencias, puesto que la misma representa un grupo de puntuaciones sistemáticas en sus concernientes categorías, además, se empleó la agrupación de cada una de las preguntas por dimensiones para conseguir la información necesaria de las variables aportando así a su posterior correlación, la cual fue interpretada estadísticamente para definir la relación existente entre las variables. Los datos fueron analizados a través de la técnica estadística de $\mathrm{R}$ de Pearson. 


\section{Resultados y discusión}

Tabla 2. Participación de artesanos por género.

\begin{tabular}{llllll}
\hline & & Frecuencia & Porcentaje & $\begin{array}{l}\text { Porcentaje } \\
\text { válido }\end{array}$ & $\begin{array}{l}\text { Porcentaje } \\
\text { acumulado }\end{array}$ \\
\hline Válido & Masculino & 16 & 11,0 & 11,0 & 11,0 \\
& Femenino & 129 & 89,0 & 89,0 & 100,0 \\
& Total & 145 & 100,0 & 100,0 & \\
\hline
\end{tabular}

Fuente: encuesta a los artesanos de Pisac.

Según la tabla 2 se puede apreciar que, del total de los artesanos del poblado de Pisac en el año 2019 , el $89 \%$ es del género femenino y $11 \%$ de los artesanos es del género masculino.

La tabla permite inferir que la población femenina está dedicada a la actividad turística, mediante las labores de artesanía con características de su localidad. Los varones en su mayoría se dedican a otras actividades económicas de su localidad. El resultado es similar con los estudios de Barrientos (2014) respecto a las actividades por género, donde encontró que la mujer en Amantaní- Puno juega un papel importante en la actividad textil y comercio y no precisamente en los suyos (parcialidades) que reciben mayor afluencia turística, sino en suyos que tienen limitaciones de equipamiento en cuanto a servicios turísticos.

Tabla 3. Percepción de la promoción turística.

\begin{tabular}{llllll}
\hline & & Frecuencia & Porcentaje & $\begin{array}{l}\text { Porcentaje } \\
\text { válido }\end{array}$ & $\begin{array}{l}\text { Porcentaje } \\
\text { acumulado }\end{array}$ \\
\hline Válido & Mala & 64 & 44,1 & 44,1 & 44,1 \\
& Regular & 70 & 48,3 & 48,3 & 92,4 \\
& Buena & 11 & 7,6 & 7,6 & 100,0 \\
& Total & 145 & 100,0 & 100,0 & \\
\hline
\end{tabular}

Fuente: encuesta a los artesanos de Pisac.

La tabla 3 muestra que el $48.3 \%$ de artesanos del poblado de Pisac respondieron que es regular la promoción turística, debido a que la municipalidad realiza algunas acciones de comunicación para los consumidores de productos artesanales, sus características y su importancia social y cultural, de esta manera incentivan a los consumidores para que los adquieran. Esto significa proporcionar a los consumidores el conocimiento de los atractivos y de la infraestructura existente, diferenciando las de la competencia, inspirando confianza y credibilidad (Castillo \& Castaño, 2015). Son estas algunas particularidades de promoción turística que deberían ser tratadas con esmero y visión de desarrollo local.

Por otro lado, el $44.14 \%$ de artesanos indican que es mala, ya que la municipalidad no promociona adecuadamente los centros arqueológicos que se tiene en el poblado y los productos artesanales. En este contexto, la cuestión político administrativa, en la que los poderes locales son los encargados y capaz de favorecer e impulsar el desarrollo del potencial socioeconómico local, enfrentando $\mathrm{y}$ resolviendo las dificultades administrativas en la promoción (Paredes, 2009).

Sin embargo, para hacer una buena promoción turística se debe realizar un conjunto de actividades como campañas, capacitaciones, charlas informativas para que los pobladores puedan inmiscuirse en el desarrollo de sus localidades; así como, el uso de la internet para promocionar un producto o servicio turístico para los consumidores. Como confirma en su estudio Toselli et al. (2020), que para promocionar utilizan páginas web, de redes sociales, folletos, entrevistas radiales $\mathrm{y} / \mathrm{o}$ televisivas en medios locales, revistas especializadas y participación en Ferias, stands, jornadas académicas. Al igual que Cayo y Apaza (2017) donde indican que las fuentes de información que facilitan el acceso son folletos turísticos, personal del área de ventas e Internet (TICs). Como se puede ver, que los medios de comunicación son importantes para promocionar los productos turísticos de los lugares donde cuentan con este patrimonio. 
Tabla 4. Percepción de la oferta turística.

\begin{tabular}{llllll}
\hline & & Frecuencia & Porcentaje & $\begin{array}{l}\text { Porcentaje } \\
\text { válido }\end{array}$ & $\begin{array}{l}\text { Porcentaje } \\
\text { acumulado }\end{array}$ \\
\hline Válido & Mala & 42 & 29,0 & 29,0 & 29,0 \\
& Regular & 90 & 62,1 & 62,1 & 91,0 \\
& Buena & 13 & 9,0 & 9,0 & 100,0 \\
& Total & 145 & 100,0 & 100,0 & \\
\hline
\end{tabular}

Fuente: encuesta a los artesanos de Pisac.

La tabla 4 muestra que, el $62.1 \%$ de artesanos respondieron que es regular la oferta turística que hace el poblado de Pisac, debido a que ellos consideran que los productos ofrecidos no son muy variados, el $29 \%$ respondieron que es mala, ya que la variedad de algunos productos es casi nula.

Este resultado puede deberse a que en Pisac no exista claramente definido un plan de promoción turística, similar como hallaron González, Benítez y Basantes (2014) en Yachay - Ecuador, donde la oferta turística en Yachay no cuenta con un producto turístico definido, a pesar que la zona cuenta con varios atractivos turísticos, pero, sin estudio técnico que dimensione el potencial turístico para proyectar los servicios a ofertar en base a las necesidades de la demanda de turismo. Considerando que el turismo es uno de los ejes de desarrollo de los países, (Solari \& Pérez, 2005) no puede entenderse aislado del resto del desarrollo de las actividades locales, se debe a ellas y es preciso que regrese a ellas fortaleciéndolas $y$ vigorizándose, en una interrelación de mutua complementariedad. Fernández-Quero y Navarro (2020) en el desarrollo local endógeno se sostiene en el intento de la creación de riqueza aprovechando todo el potencial posible que éste ofrece, con la participación de todos para un desarrollo turístico sostenible.

Tabla 5. Expectativas de los turistas sobre la promoción municipal de los productos artesanales de textilería tradicional.

\begin{tabular}{llllll}
\hline & Frecuencia & Porcentaje & $\begin{array}{l}\text { Porcentaje } \\
\text { válido }\end{array}$ & $\begin{array}{l}\text { Porcentaje } \\
\text { acumulado }\end{array}$ \\
\hline Válido & Totalmente en desacuerdo & 33 & 22,8 & 22,8 & 22,8 \\
& En desacuerdo & 62 & 42,8 & 42,8 & 65,5 \\
& Ni de acuerdo ni en desacuerdo & 10 & 6,9 & 6,9 & 72,4 \\
& De acuerdo & 38 & 26,2 & 26,2 & 98,6 \\
& Totalmente de acuerdo & 2 & 1,4 & 1,4 & 100,0 \\
& Total & 145 & 100,0 & 100,0 & \\
\hline
\end{tabular}

Fuente: encuesta a los artesanos de Pisac.

Según la tabla 5 se aprecia que, el $42.8 \%$ de artesanos respondieron estar en desacuerdo con la promoción municipal de los productos artesanales de textilería tradicional, cubre las expectativas de los turistas, debido a que los turistas no se muestran del todo contentos con la promoción turística, pero, el $1.4 \%$ están totalmente de acuerdo, ya sea porque ellos sí observaron una buena reacción de los turistas.

El desarrollo debería partir desde los gobiernos locales que son los responsables en conducir el destino de sus pueblos, promoviendo la oferta de sus recursos turísticos potenciales. Narváez (2015) el gobierno local, juntamente con los poderes provincial y nacional, juegan un rol clave en este proceso, invirtiendo en infraestructura y servicios, implementando políticas públicas de desarrollo turístico y la atracción de inversiones, así como, el fomento del asociativismo empresarial.

Cuando son promocionados los recursos turísticos, los visitantes concurren a dichos recursos a fin de consumirlo y disfrutarlo. Así como se dio en la provincia de Entre Ríos - Argentina donde una vez revelado los sitios, los visitantes tuvieron la posibilidad de adquirir artesanías elaborados en madera, cuero, y el típico mate (Tosell et al., 2020). Tras la promoción puede surgir iniciativas de acciones conjuntas $u$ organizaciones que apuesten del desarrollo. Como lo demuestran en su estudio Peña-Hernández et al. (2020) la integración de las MIPYMES turísticas y visitantes que activan la economía con productos locales: artesanías de piel, curtidoras dentro del sistema de las MIPYMES, vendedores ambulantes (internos y 
externos), transporte público, otros prestadores de servicios de alimentos y bebidas. Son experiencias que pueden ser replicadas en lugares turísticos para integrar los actores mediante estrategias de organizaciones conjuntas para un crecimiento y desarrollo económico local.

Tabla 6. Percepción sobre expectativas de los turistas de la promoción municipal de la gastronomía local.

\begin{tabular}{llllll}
\hline & Frecuencia & Porcentaje & $\begin{array}{l}\text { Porcentaje } \\
\text { válido }\end{array}$ & $\begin{array}{l}\text { Porcentaje } \\
\text { acumulado }\end{array}$ \\
\hline Válido & Totalmente en desacuerdo & 21 & 14,5 & 14,5 & 14,5 \\
& En desacuerdo & 38 & 26,2 & 26,2 & 40,7 \\
& Ni de acuerdo ni en desacuerdo & 49 & 33,8 & 33,8 & 74,5 \\
& De acuerdo & 30 & 20,7 & 20,7 & 95,2 \\
& Totalmente de acuerdo & 7 & 4,8 & 4,8 & 100,0 \\
& Total & 145 & 100,0 & 100,0 & \\
\hline
\end{tabular}

Fuente: encuesta a los artesanos de Pisac.

La tabla 6 presenta que, el $33.8 \%$ de los artesanos se mostraron indiferentes respecto a las expectativas de los turistas acerca de la gastronomía, sin embargo, solo el $4.8 \%$ están totalmente de acuerdo en que las expectativas del turista en la gastronomía son cubiertas gracias a la promoción de la municipalidad, esto puede deberse a que la municipalidad no promociona adecuadamente la gastronomía local, dando énfasis en otros productos para ofrecer a los turistas.

El resultado contradice con Cayo y Arcaya (2013) en su estudio sobre satisfacción de los turistas en Puno con la comida ligera y los restaurantes reconocidos debido a que estos atributos no eran considerados tan importantes, no obstante, superaron sus expectativas; en vista que la actividad turística gastronómica genera el desarrollo local beneficiando a los pobladores, debido a la activación de la economía local (PeñaHernández et al., 2020).

Sin embargo, Millán et al. (2014) en su conclusión indican que se debe conocer el perfil del consumidor de turismo gastronómico y ofertar un producto a su medida; para ello es necesario comunicar de los servicios y productos ofertados y crear un sistema de señalización de rutas gastronómicas, bodegas, industrias alimentarias, alojamientos, restaurantes, entre otros. De esa forma el turismo gastronómico se perfila como una opción viable para el desarrollo de algunos de los pueblos que habitan la tierra (Bringas, 2004).

Tabla 7. Percepción sobre calidad de los productos y servicios brindados a los turistas en el distrito de Pisac.

\begin{tabular}{llllll}
\hline & Frecuencia & Porcentaje & $\begin{array}{l}\text { Porcentaje } \\
\text { válido }\end{array}$ & $\begin{array}{l}\text { Porcentaje } \\
\text { acumulado }\end{array}$ \\
\hline Válido & Totalmente en desacuerdo & 1 &, 7 &, 7 &, 7 \\
& En desacuerdo & 21 & 14,5 & 14,5 & 15,2 \\
& Ni de acuerdo ni en desacuerdo & 38 & 26,2 & 26,2 & 41,4 \\
& De acuerdo & 74 & 51,0 & 51,0 & 92,4 \\
& Totalmente de acuerdo & 11 & 7,6 & 7,6 & 100,0 \\
& Total & 145 & 100,0 & 100,0 & \\
\hline
\end{tabular}

Fuente: encuesta a los artesanos de Pisac.

La tabla 7 muestra que, el $51 \%$ de los artesanos dicen estar de acuerdo respecto al consumo de productos y servicios de los turistas, por otro lado, solo el $0.7 \%$ están totalmente en desacuerdo, esto se puede inferir que los productos y servicios ofrecidos en Pisac son de buena calidad.

Este resultado permite inferir que los productos y servicios que se ofrecen en Pisac son aceptables para el segmento de turistas. Diferenciándose con el estudio de Fernández y Bezerra (2015) en PIPA - Brasil, donde observaron la predominancia de brechas negativas, los servicios ofrecidos estaban por debajo de las expectativas de los turistas. De los 28 atributos utilizados en la investigación, 19 presentaron brechas negativas y solo 9 presentaron positivamente. Un producto turístico acompañado de la amabilidad de los pobladores, el calor humano y servicial, expresado a través de sus diferentes actitudes positivas, puede generar el sentimiento 
de satisfacción en el visitante. Como indican los autores, Cayo y Apaza (2017) la imagen es satisfactoria para el turista por el acogimiento en los servicios, la hospitalidad de los habitantes y por presentar diversidad de escenarios naturales.

Tabla 8. Percepción de la demanda Turística.

\begin{tabular}{|c|c|c|c|c|c|}
\hline & & Frecuencia & Porcentaje & $\begin{array}{l}\text { Porcentaje } \\
\text { válido }\end{array}$ & $\begin{array}{l}\text { Porcentaje } \\
\text { acumulado }\end{array}$ \\
\hline \multirow[t]{4}{*}{ Válido } & Mala & 15 & 10,3 & 10,3 & 10,3 \\
\hline & Regular & 86 & 59,3 & 59,3 & 69,7 \\
\hline & Buena & 44 & 30,3 & 30,3 & 100,0 \\
\hline & Total & 145 & 100,0 & 100,0 & \\
\hline
\end{tabular}

Fuente: encuesta a los artesanos de Pisac.

Según la tabla 8 se aprecia que, el $59.3 \%$ de los artesanos del poblado de Pisac respondieron que es regular la demanda turística, $30.3 \%$ de los encuestados respondieron que es buena, ya que los artesanos consideran que los productos y servicios demandados por los turistas satisfacen plenamente las necesidades, puesto que ellos le brindan productos de calidad y el 10,3\% respondieron que es mala, ya que consideran que la municipalidad debería promover más el turismo.
La demanda turística tiene que ver muchas veces con el crecimiento económico de los turistas y de sus países, además, de la seguridad que puede ofrecer los destinos turísticos. Una medida adecuada para incentivar la demanda turística y consolidar el crecimiento del turismo consiste en mantener una estabilidad socio-política, adecuada seguridad ciudadana y conservar coherencia económica, inspirando una imagen de confianza que influya en los potenciales turistas (Gardella et al. 2005).

Tabla 9. Percepción sobre satisfacción de las necesidades de los turistas en cuanto a los productos y servicios demandados.

\begin{tabular}{llllll}
\hline & Frecuencia & Porcentaje & $\begin{array}{l}\text { Porcentaje } \\
\text { válido }\end{array}$ & $\begin{array}{l}\text { Porcentaje } \\
\text { acumulado }\end{array}$ \\
\hline Válido & Totalmente en desacuerdo & 4 & 2,8 & 2,8 & 2,8 \\
& En desacuerdo & 20 & 13,8 & 13,8 & 16,6 \\
& Ni de acuerdo ni en desacuerdo & 45 & 31,0 & 31,0 & 47,6 \\
& De acuerdo & 69 & 47,6 & 47,6 & 95,2 \\
& Totalmente de acuerdo & 7 & 4,8 & 4,8 & 100,0 \\
& Total & 145 & 100,0 & 100,0 & \\
\hline
\end{tabular}

Fuente: encuesta a los artesanos de Pisac.

Según la tabla 9 se aprecia que, el $47.6 \%$ de los artesanos están de acuerdo respecto a que, los productos y servicios demandados por los turistas satisfacen plenamente las necesidades del consumidor, por otro lado, solo el $2.8 \%$ están totalmente en desacuerdo, esto se puede inferir que los productos y servicios son buenos y adecuados, por ello, que se da la aceptación de parte de los turistas.

Según el estudio realizado por Cayo y Arcaya (2013) se resalta que los lugares y atractivos turísticos, así como el alojamiento y la alimentación son aspectos más importantes para sentirse satisfechos y más aún, la seguridad en los lugares visitados por el turista. Este estudio tiene relación con los resultados de la investigación, donde los artesanos testimonian que el consumidor se siente satisfecho luego de consumirlo los diversos atractivos turísticos patrimoniales, el parque arqueológico de Pisac compuesto por sitios arqueológicos, las referencias históricas culturales, la artesanía y la gastronomía. 
Tabla 10. Percepción de motivación de los turistas para su visita al distrito de Pisac.

\begin{tabular}{llllll}
\hline & Frecuencia & Porcentaje & $\begin{array}{l}\text { Porcentaje } \\
\text { válido }\end{array}$ & $\begin{array}{l}\text { Porcentaje } \\
\text { acumulado }\end{array}$ \\
\hline Válido & & & 1,4 & 1,4 \\
& Totalmente en desacuerdo & 2 & 1,4 & 4,8 & 6,2 \\
& En desacuerdo & 7 & 4,8 & 32,4 & 38,6 \\
& Ni de acuerdo ni en desacuerdo & 47 & 32,4 & 40,0 & 78,6 \\
& De acuerdo & 58 & 40,0 & 21,4 & 100,0 \\
& Totalmente de acuerdo & 31 & 21,4 & 100,0 & \\
& Total & 145 & 100,0 & & \\
\hline
\end{tabular}

Fuente: encuesta a los artesanos de Pisac.

Según la tabla 10 se aprecia que, el $40 \%$ de los artesanos están de acuerdo respecto a que, los productos y servicios ofrecidos por los artesanos motiva a los turistas su visita al distrito, por otro lado, solo el $1.4 \%$ están totalmente en desacuerdo, esto se puede interpretar que los productos y servicios son como un atractivo que posee el distrito de Pisac para atraer turistas.

Además, de los servicios y productos que pueden ofrecer los pobladores del lugar, puede motivar otros factores como refieren Cayo y Apaza (2017) en Puno, descanso/relajante, nuevos lugares, disfrutar tiempo libre con familia y amigos; los atractivos, como el lago Titicaca, la festividad de la Virgen de la Candelaria. Otro de los motivos para visitar es que el turista pudo haberse informado de la existencia de productos turísticos naturales y otros relacionados que le llamen la atención para concurrir. Florensa et al. (2020) para visitar los espacios naturales protegidos del Parque Nacional de Aigüestortes en Lleida indagaron que el 64.08 \% conocía desde siempre, 21.29 le recomendaron las amistades, el $7.76 \%$ por internet y revistas de montaña. Entonces, los motivos para visitar los lugares turísticos naturales y modernos pueden ser indistintos.

Tabla 11. Percepción sobre promoción municipal y participación ciudadana.

\begin{tabular}{llllll}
\hline & Frecuencia & Porcentaje & $\begin{array}{l}\text { Porcentaje } \\
\text { válido }\end{array}$ & $\begin{array}{l}\text { Porcentaje } \\
\text { acumulado }\end{array}$ \\
\hline Válido & Totalmente en desacuerdo & 23 & 15,9 & 15,9 & 15,9 \\
& En desacuerdo & 43 & 29,7 & 29,7 & 45,5 \\
& Ni de acuerdo ni en desacuerdo & 24 & 16,6 & 16,6 & 62,1 \\
& De acuerdo & 54 & 37,2 & 37,2 & 99,3 \\
& Totalmente de acuerdo & 1 &, 7 &, 7 & 100,0 \\
& Total & 145 & 100,0 & 100,0 & \\
\hline
\end{tabular}

Fuente: encuesta a los artesanos de Pisac.

La tabla 11 se aprecia que, el $37.2 \%$ de los artesanos están de acuerdo respecto a que, la promoción municipal fomenta la participación ciudadana para analizar las necesidades y dificultades con el fin de mejorar la promoción turística, además, el 0.7 $\%$ mencionan estar totalmente de acuerdo, lo que se llega a determinar que la municipalidad sí se preocupa por la colaboración de la población en las disposiciones concernientes al turismo.

Para desafiar el desarrollo requiere implementar procesos que permitan lograr las metas y objetivos formulados con la participación de los actores locales. El desarrollo local significa proceso de innovación integral, referidos a los aspectos sociales, económicos, culturales, políticos $\mathrm{y}$ administrativos (Cárdenas, 2002). Se cimienta y asegura en una participación social que es capaz de construir, decantar y acumular capital social y simbólico, identidad territorial, ciudadanía y transformar/fortalecer la institucionalidad local (Solari \& Pérez, 2005). Lo cual permitiría que los pobladores encuentren mejores condiciones de vida y desarrollo sostenible producto de la participación conjunta. Como indica Herbert (2001) que una ciudad sostenible es aquella que se organiza de manera que posibilite que todos sus ciudadanos satisfagan sus propias necesidades y que eleven su bienestar sin dañar el entorno natural $\mathrm{y}$ sin poner en peligro las condiciones de vida de otras personas. 
Tabla 12. La promoción municipal de la actividad turística en relación al mejoramiento de la calidad de vida del distrito de Pisac.

\begin{tabular}{llllll}
\hline & Frecuencia & Porcentaje & $\begin{array}{l}\text { Porcentaje } \\
\text { válido }\end{array}$ & $\begin{array}{l}\text { Porcentaje } \\
\text { acumulado }\end{array}$ \\
\hline Válido & Totalmente en desacuerdo & 8 & 5,5 & 5,5 & 5,5 \\
& En desacuerdo & 29 & 20,0 & 20,0 & 25,5 \\
& Ni de acuerdo ni en desacuerdo & 37 & 25,5 & 25,5 & 51,0 \\
De acuerdo & 59 & 40,7 & 40,7 & 91,7 \\
& Totalmente de acuerdo & 12 & 8,3 & 8,3 & 100,0 \\
Total & 145 & 100,0 & 100,0 & \\
\hline
\end{tabular}

Fuente: encuesta a los artesanos de Pisac.

Según la tabla 12 se aprecia que, el $40.7 \%$ de los artesanos están de acuerdo respecto a que, mediante la promoción municipal de la actividad turística se haya mejorado la calidad de vida del distrito de Pisac, solo el $5.5 \%$ está totalmente en desacuerdo, lo que se llega a determinar que la promoción turística fue efectiva y alcanzó aumentar la calidad de vida.

Como se apreció en la tabla, turismo contribuye en la mejora de calidad de vida de los actores locales y por ende la economía local. Narváez (2015) el turismo puede generar riqueza en términos de creación de empresas y empleos diversificados, pero, solo si la estrategia de desarrollo de la actividad se plantea a partir de ventajas comparativas existentes en la localidad, verdaderas y sostenibles. Sin embargo, mientras no se utiliza la actividad turística de forma sistemática, el desarrollo local posiblemente sea débil o inadecuado.

Los resultados de Peña-Hernández et al. (2020) se asemeja con los resultados de la investigación, donde la comunidad local del municipio de Villa de Tezontepec inmersa en el sistema turístico ha logrado una mejora tanto en su calidad de vida como en su desarrollo personal y laboral, allí la generación de empleo no solo se limitó al ámbito familiar, sino que tuvo alcance local. Asimismo, el desarrollo y crecimiento español fue debido al sector turismo, es y ha sido uno de los principales sectores generadores de crecimiento económico de España (García \& Barrena, 2013). Por tanto, para el desarrollo local en lugares, regiones y países turísticos es de suma importancia la articulación entre todos los actores locales para impulsar el crecimiento económico, la mejora de calidad de vida y social.

No obstante, es importante considerar que los pobladores comprendan el significado del desarrollo local mediante las actividades turísticas locales. Narváez (2015) el turismo puede aportar significativamente al desarrollo de una localidad, solo si los actores y gestores están de acuerdo sobre los modos de emprender ese desarrollo y confían en las potencialidades de esta actividad para contribuir al logro de sus metas.

Tabla 13. Correlación entre Promoción Turística y Desarrollo Local.

\begin{tabular}{llll}
\hline & & Promoción Turística & Desarrollo Local \\
\hline Promoción Turística & Correlación de Pearson & 1 &, $473^{* *}$ \\
& Sig. (bilateral) & &, 000 \\
& N & 145 & 145 \\
Desarrollo Local & Correlación de Pearson &, $473^{* *}$ & 1 \\
& Sig. (bilateral) &, 000 & \\
& $\mathrm{~N}$ & 145 & 145 \\
\hline **. La correlación es significativa en el nivel 0,01 (bilateral).
\end{tabular}

La tabla 13 muestra una correlación positiva de 0.473 , cuya significancia es 0,000 , este valor es menor a 0,05 que significa que sí existe una relación significativa entre las variables Promoción Turística y Desarrollo Local en el distrito de Pisac. Por tanto, se acepta la hipótesis de la investigación en el sentido que la promoción turística tiene una relación significativa con el desarrollo local y se rechaza la hipótesis nula.

En el estudio realizado por Barrientos (2014) sus resultados son similares, donde la percepción de los pobladores sobre el turismo en la isla Amantaní - Perú es positiva, porque les ha permitido mejorar 
el aspecto económico de los pobladores, por ende, el desarrollo local. Cuando existe desarrollo local, ocurre una transformación cultural, los procesos de transformación cultural encuentran en el sujeto el escenario concreto para la materialización de este tipo de visión (Echeverry et al., 2013). Se puede deducir que el turismo sostenible puede transformar culturalmente a los actores sociales del lugar, desde la calidad de vida, educación, las costumbres, entre otros, para brindar un mejor servicio a los visitantes nacionales y extranjeros.

\section{Conclusiones}

El turismo es una actividad económica dinámica de los pueblos que cuentan con recursos turísticos, porque es una fuente de ingreso económico para las familias dedicadas al turismo y por ende el desarrollo de su localidad. Por tanto, se identificó que la promoción turística guarda una relación positiva y significativa con el desarrollo local, es decir, que, si la promoción turística se desarrolla de forma adecuada, contribuirá al desarrollo local del distrito, porque cuanto mayor y mejor se hace la promoción turística, mayor o mejor será el desarrollo local.

La oferta y demanda de productos turísticos es muy importante para que se produzca la economía dinámica local, en beneficio de los actores locales. Entre la oferta turística y el desarrollo local existe una relación positiva y significativa con el desarrollo local, es decir que, si la oferta turística mejora, llámese esto una buena promoción de productos y servicios turísticos y el mejor trato humano a los visitantes ayudará al desarrollo local del distrito. Asimismo, la demanda turística y el desarrollo local existe una relación positiva y significativa con el desarrollo local, es decir que, si la demanda turística aumenta, la mayor concurrencia de los turistas generará mayores ingresos para la población y favorecerá al desarrollo local del distrito.

La limitación que se tuvo durante la investigación fue que algunas autoridades y artesanos locales no quisieron colaborar con el estudio, mostrando su indiferencia al momento de la entrevista, actitudes como estas que no han permitió que la proximidad a la precisión de los resultados no sean como los esperados.

Los resultados de la investigación han permitido identificar los posibles temas de investigación, como la necesidad de conocer la relación de las variables apoyo financiero de fuentes públicos y privados con la competitividad de artesanía local para ofrecer a los turistas nacionales e internacionales; asimismo, se debe investigar la satisfacción de los consumidores de los productos turísticos para conocer la calidad de oferta turística.

\section{Referencias}

Alburquerque, F. (2007). Desarrollo local en América Latina: Oportunidades y desafios para el trabajo decente. Departamento de Integración de Políticas Grupo de Políticas Nacionales Oficina Internacional del Trabajo Ginebra. http://www.ilo.int/wcmsp5/groups/ public/---dgreports/---integration/documents/ publication/wcms_099052.pdf

Barrientos, K.N. (2014). Beneficios Socioeconómicos y ecológicos del turismo en la islaAmantaní-Perú, 2013.Comuni@cción: revista de investigación en comunicación y desarrollo, 5(2), 48-58. http://www.scielo. org.pe/pdf/comunica/v5n2/a05v5n2.pdf

Bringas, J.(2004). El turismoalternativo:una opción para el desarrollo local en dos comunidades indígenas de Baja California. Economía, Sociedad y Territorio, 4(15), 551-558. https:// www.redalyc.org/pdf/111/11101508.pdf

Ibañez, R. y Cabrera, V. (2011). Teoria General del Turismo: Enfoque Global y Nacional. Universidad Autonoma de Baja California. http://uabcs.mx/difusion2017/webroot/files/ libros/pdf/184_20160908023838.pdf

Calderón, A. M. (2017). Turismo sostenible y desarrollo local en el distrito de Ccorca Cusco 2016. (Tesis pre grado), Universidad Peruana Austral del cusco. Cusco. http:// repositorio.uaustral.edu.pe/handle/ $\underline{\text { UAUSTRAL/19 }}$

Cárdenas, N. (2002). El desarrollo local su conceptualización y procesos. Provincia, (8), 53-76. $\quad$ https://www.redalyc.org/ pdf $/ 555 / 55500804 . p d f$

Carvajal, A. (2011). Desarrollo Local: Manual Basico para Agentes de Desarrollo Local $y$ Otros Actores. Eumed.net http://www. bibliotecavirtualrs.com/wp-content/ 
uploads/2011/06/desarrollo local manual basico.pdf

Castillo, P. M. y Castaño, M. V. (2015). La promoción turística a traves de técnicas tradicionales y nuevas. Estudios y perspectivas en Turismo, 24, 737-757. DOI:10.13140/ $\underline{R G \cdot 2 \cdot 1.2786 .0329}$

Cayo, N.E. Y Apaza, A. (2017). Evaluación de la ciudad de Puno como destino turístico - Perú. Comuni@cción: revista de investigación en comunicación y desarrollo, 8(2), 116 - 124. http://www.scielo.org.pe/pdf/comunica/v8n2/ a05v8n2.pdf

Cayo, N.E. Y Arcaya, L.E. (2013). Grado de satisfacción de los servicios turísticos en la ciudad de Puno 2011 - Perú.Comuni@cción: revista de investigación en comunicación $y$ desarrollo. 4(1), 28-37. https://dialnet. unirioja.es/servlet/articulo? codigo $=4491733$

Cárdenas, N. (2002). El desarrollo local su conceptualización y procesos. Provincia, (8), 53 - 76. https://www.redalyc.org/ pdf/555/55500804.pdf

DeLugo,E.L.(2000).Interpretación delpatrimonio arqueológico. Anthropos. https://dialnet. unirioja.es/servlet/articulo?codigo $=3034564$

Di Pietro, P. J. (2001). Hacia un desarrollo integrador y equitativo: una introduccion al desarrollo local. CICCUS.

Dueñas-Ocampo, S., Perdomo-Ortiz, J. \& Villa Castaño, L.E. (2021) La separación entre sostenibilidad organizacional y desarrollo sostenible: una reflexión sobre herramientas emergentes para disminuir la brecha. Innovar, 31(80) 113-128. 10.15446/in-novar. v31n 80.93668

Echeverry, R. R., Medina, V. J. Y Silva, C. T. (2013). El desarrollo local desde una perspectiva sociocultural de la competitividad. Cuadernos de Administración, 29(49), 45-54. https:// bibliotecadigital.univalle.edu.co/bitstream/ handle/10893/6492/el\%20desarrollo\%20 local.pdf?sequence $=1 \&$ is Allowed $=y$
Fernández, D. Y Bezerra, D. N. (2015). Factores de atractividad y calidad de los servicios turísticos en el destino Pipa - Brasil. Estudios y Perspectivas en Turismo, 24, $205-221$

Fernández-Quero, J. L. y Navarro F. A. (2020). Identificación de recursos turísticos potenciales importantes por criterios de singularidad identitaria y universal. El municipio de Ugíjar en la Comarca de las Alpujarras. Cuadernos de Turismo, (45), 141165. 10.6018/turismo.426071

Florensa, R.M.; Colom, A. y Maza, M. T. (2020). Análisis ACP, CHAID y PLS_SEM de la satisfacción de visitantes de espacios naturales protegidos. Aplicación al Parque Nacional de Aigüestortes en Lleida. Cuadernos de Turismo, (45), 167-195. 10.6018/turismo.426081

Forneris, M. (2012). Turismo y desarrollo local en Chacabuco: creando cimiento para una construcción conjunta. (Tesis de licenciatura), Universidad Nacional de la Plata. Buenos Aires. $\quad$ http://sedici.unlp.edu.ar/bitstream/ handle/10915/22568/Documento completo.. pdf? sequence $=3$

García, T. Y Barrena, R. (2013). Preferencias del visitante de establecimientos de turismo rural. Estudio en Navarra. Cuadernos de Turismo, (32), 141-153. https://revistas.um.es/turismo/ article/view/177491/149201

Gardella, R. J.; Lupo, F. J.; Aguayo, E. (2005). Mercado turístico argentino. Análisis de su demandainternacional.EstudiosyPerspectivas en Turismo, 14(2), 127-138. https://www. redalyc.org/pdf/1807/180713886002.pdf

González, A.; Benítez, N.M. Y Basantes A.V. (2014). La oferta y demanda turística en Yachay "La Ciudad del Conocimiento", Ecuador. Revista Interamericana de Ambiente y Turismo, 10(1), 67-78. 10.4067/ riatvol10iss 1pp67-77\%250718-235X

Gurria, M. (1997). Introduccion al Turismo. Trillas.

Herbert, G. 2001. Creando ciudades sostenibles. Tilde. 
Hernández, R., Fernández, C. y Baptista, M.P. (2010). Metodología de la investigación. https://www.icmujeres.gob.mx/wp-content/ uploads/2020/05/Sampieri.Met.Inv.pdf

Hernández R, Fernández C y Baptista M P. (2014). Metodología de la Investigación. Mc Graw Hill. http://observatorio.epacartagena.gov.co/ wp-content/uploads/2017/08/metodologiade-la-investigacion-sexta-edicion. compressed.pdf

Hurtado, J. (1998). Metodología de la Investigación Holistica. Fundación Sypal

Millán, G.; Morales, E. y Pérez, L. (2014). Turismo gastronómico, denominaciones de origen y desarrollo rural en Andalucía: situación actual. Boletín de la Asociación de Geógrafos Españoles, 65(65), 113-137. DOI:10.21138/ bage. 1746

Monge-Rodriguez. Y. (2016). El desarrollo loca. Enfoques para su conceptualización. OLIMPIA. Revista de la Facultad de Cultura Física de la Universidad de Granma, 13(39), 226-238.

Narváez, E.L. (2015). El turismo alternativo: una opción para el desarrollo local RevIISE - Revista de Ciencias Sociales y Humanas, 6(6), 9-18.

Paredes, P. (2009). Desarrollo Local: Gestion, Estrategia, Elementos, Caracteristicas, Dimensiones y Agentes. Voxlocalis, (23), 1-14. https://old.voxlocalis.net/revistas/ num23/doc/percy.pdf

Peña-Hernández, A. E.; Reyes, J. B.; VillafañaRivera, F.; Flores-Amador, C. y EspitiaLópez, J. (2020). Participación de las MIPYMES al desarrollo local, resultado de la actividad turística gastronómica: caso de estudio. Cientifica, 24(1), 49-58. 10.46842/ ipn.cien.v24n1a06

Pérez-García, A. y Torres-Valdés, R. (2019). Las agencias de empleo y desarrollo local, y el uso de las redes sociales en la promoción turística relacional. Innovar, 29(72), 77-88. 10.15446/ innovar.v29n72.77933

Pulido-Fernández, J. I., y López-Sánchez, Y. (2016). La cadena de valor del destino como herramienta innovadora para el análisis de la sostenibilidad de las políticas turísticas. El caso de España. Innovar, 26(59), 155-176. 10.15446/innovar.v26n59.54369.

Toselli, C.; Takáts, A. y Traverso, L. D. (2020). Análisis de la sostenibilidad en emprendimientos turísticos ubicados en áreas rurales y naturales. Estudios de caso en la provincia de entre ríos, Argentina. Cuadernos de turismo (45), 461-489. 10.6018/ turismo.426211

Rojas, R. (2013). Guía para realizar investigaciones sociales. Plaza y Valdés. https://raulrojassoriano.com/cuallitlanezi/ wp-content/themes/raulrojassoriano/assets/ libros/guia-realizar-investigaciones-socialesrojas-soriano.pdf

Sanchis, A. y Olcina, L. (1995). El desarrollo del turismo rural y sus repercusiones. Papers de turismo, 17, 89-101. http://www. papersdeturisme.gva.es/ojs/index.php/ Papers/article/view/296/253

Sancho, A. (2008). Introducción al Turismo. OMT. http://www.utntyh.com/wp-content/ uploads/2011/09/introduccion-al-turismoomt.pdf

Sekaran, U. (2003). Research methods for business. 4ta edición: John Wiley \& Sons

Socatelli, M. (2013). Mercadeo Aplicado al Turismo. La Comercialización de Servicios Productos y Destinos Turísticos Sostenibles. Intermark.

Solari, A. Y Pérez, M. (2005). Desarrollo local y turismo: relaciones, desavenencias y enfoques. Economía y Sociedad, 10(16), 49-64. https:// www.redalyc.org/pdf/510/51001603.pdf 